\title{
ИЗМЕНЕНИЕ КЛИМАТА о. КУНАШИР (КУриЛЬский архипелаГ) В ТЕЧЕНИЕ 11- 9-Й МОРСКИХ ИЗОТОПНЫХ СТАДИЙ
}

\author{
Пушкарь В. С. \\ ФГБУН Дальневосточный геологический институт ДВО РАН, г. Владивосток \\ E-mail: vlpushkar@mail.ru,pushkar@fegi.ru
}

\begin{abstract}
Среднеплейстоценовые отложения верхней части головнинской свиты о. Кунашир (Курилы) образовались в межледниково-ледниковые климатические и трансгрессивно-регрессивные циклы, соответствующие 11-9-й морским изотопным стадиям (МИС). Во время трансгрессивной фазы МИС-11 уровень моря был на 20-25 м выше современного и до 5 м выше современного во время МИС-9. Слои туфа и перерывы в осадконакоплении соответствуют регрессивной фазе (МИС-10). Различия в условиях формирования отложений во время МИС11(424-374 тыс. лет назад) и МИС-9 (337-300 тыс. лет назад) позволяют предположить, что теплый климат и высокое положение уровня моря в течение длинной межледниковой МИС-11 были вызваны не только вариациями солнечной инсоляции, связанными с орбитальными изменениями Земли. В этот период произошли слабые орбитальные изменения в распределении солнечной инсоляции на поверхности Земли. Условия среды МИС-11 вызваны иными причинами, которые, возможно, были связаны с изменениями уровня концентрации углекислого газа в атмосфере, регистрируемыми высокой фотосинтетической палеопродуктивностью диатомовых водорослей.
\end{abstract}

Ключевые слова: климат, трансгрессии, МИС 11-9, межледниковье, средний плейстоцен, о. Кунашир, Курилы.

DOI: $10.34078 / 1814-0998-2020-3-36-46$

\section{ВВЕДЕНИЕ}

Четвертичный период в истории Земли характеризуется как период мощных оледенений. При этом постулируется, что периодичность их экспансии и распада регулируется изменениями орбитальных параметров Земли (теория Миланковича), отраженных в вариациях изотопнокислородной кривой, построенной по бентосным фораминиферам (Lisiecki, Raymo, 2005). В дальнейшем развитии представлений о причинах периодичности оледенений и межледниковий эта теория не смогла объяснить ряд несоответствий орбитальных изменений, а следовательно, и солнечной инсоляции, ряду морских изотопных стадий (МИС). В частности, это проблема 11-й изотопной стадии (Большаков, 2010, 2014; Rohling et al., 2010). В. А. Большаков отмечает, что еe суть кроется в том, что в качестве управляющего инсоляционного сигнала рассматривается среднемесячная или суточная инсоляция под одной широтой. С этих позиций он постулирует, что эксцентриситетный инсоляционный сигнал, близкий к 100-тысячному циклу, «...является в данном случае как бы спусковым крючком, запускающим работу резонансного механизма климатической системы» (Большаков, 2010. С. 243). Но

(C) Пушкарь В. С., 2020 эта концепция также не объясняет масштабность изменений среды 11-й МИС, поскольку амплитуды орбитальных изменений этого межледниковья были весьма незначительны. Но что же тогда могло вызвать коллапс ледниковых покровов в это время (Raymo, Mitrovica, 2012)?

Многие исследователи пришли к выводу, что, кроме орбитальных параметров, на климатическую систему Земли сильнейшее влияние оказывает концентрация $\mathrm{CO}_{2}$ в атмосфере, приводящая к «парниковому эффекту» и сокращению объемов ледниковых покровов. Но изменения концентрации $\mathrm{CO}_{2}$ не связаны с орбитальными параметрами Земли и могут с ними не совпадать. Скорее всего, глобальные углеродные циклы имеют свою собственную причинно-следственную связь, которая не обусловлена ледниковой периодизацией как первопричиной (Loutre, 2003; Yin, Berger, 2010, 2012).

В связи с этим возникла и проблема изменений природной среды, включая и колебания уровня Мирового океана во время одной из самыХ экстремально теплой и длительной МИС-11 (424-374 тысяч лет назад - тыс. л. н., миндельрисс) за всю историю плейстоцена. Особенно ярко палеоклиматические изменения этого времени были проявлены в арктических и субарктических широтах Восточной Азии (Ложкин и др., 
2007, 2016; D'Anjou. et al., 2013; Wennrich et al., 2013; Lozhkin, Anderson, 2013; Недорубова, 2014, 2018; Caissie et al., 2016). Отмечено, что при решении этой проблемы необходим анализ синергетической связи глобальных (циклы Миланковича) и региональных (Берингийская суша, течения Северной Пацифики, муссонная составляющая) факторов климатогенеза (Laukhin et al., 2006; Lozhkin et al., 2007, 2017; Pushkar, Cherepanova, 2011; Melles et al., 2013).

В отношении положения уровня моря времени МИС-11 существуют три точки зрения. Одна из них основана на положении береговых линий в разрезах морских террас тектонически стабильного о. Барбадос, предполагающая повышение уровня моря не менее чем на +21 м по сравнению с современным (Hearty et al., 1999; Olson, Hearty, 2009; Hearty, 2010). Аналогичные данные получены по Аляске и Курильским островам (Пушкарь, Разжигаева, 1998, 2003; Pushkar et al., 1999; Pushkar, Razjigaeva, 2003). Другая точка зрения, основанная на аналоговых моделях изменения объемов ледников планеты и их таяния, сводится к утверждению о соответствии уровня моря времени МИС-11 уровню в голоцене или уровню межледниковой МИС-5 (Воwen, 2010; Rohling et al., 2010; Hearty, 2010) или несколько выше - до +6-13 м (Raymo, Mitrovica, 2012). Третья позиция касается катастрофического обрушения антарктических ледников во время ледникового коллапса МИС-11 и возникновения мегацунами, приведшего к формированию высокого положения береговых линий на о. Барбадос, что вызвало острую дискуссию (Hearty et al., 1999; McMurtry et al., 2007; Hearty, Olson, 2008; Raymo, Mitrovica, 2012).

Цель работы состоит в определении условий формирования отложений и выделении палеогеографических событий, соответствующих глобальным изменениям природной среды среднего плейстоцена, и выяснении возможных причин палеоклиматических особенностей и колебаний уровня моря во время резко контрастирующих между собой межледниковых МИС-11 (424-374 тыс. л. н.) и МИС-9 (337-300 тыс. л. н.).

\section{МАТЕРИАЛ И МЕТОДЫ ИССЛЕДОВАНИЯ}

Основным резервуаром накопления любых форм углерода, поглощенного из земной атмосферы, служит Мировой океан. Главную роль в этом биогеохимическом круговороте углерода играют микроскопические диатомовые водоросли, чья жизнедеятельность связана с процессом фотосинтеза. Известно, что диатомеи создают более $50 \%$ всей органической массы Мирового океана, поглощая при этом около 10 млрд т углерода ежегодно. Поэтому количество панцирей диатомей в осадках океана всецело отражает их палеопродуктивность как фотосинтетиков, связанную с концентрацией $\mathrm{CO}_{2}$ в атмосфере. Это и послужило основанием выбора диатомового анализа рабочим инструментом исследований. При интерпретации палеоклиматических условий и глубины формирования отложений использованы данные по экологии диатомей (McQuoid, Hobson, 1998; Пушкарь, Черепанова, 2001, 2008; McQuoid, Nordberg, 2003; Gebühr et al., 2009).

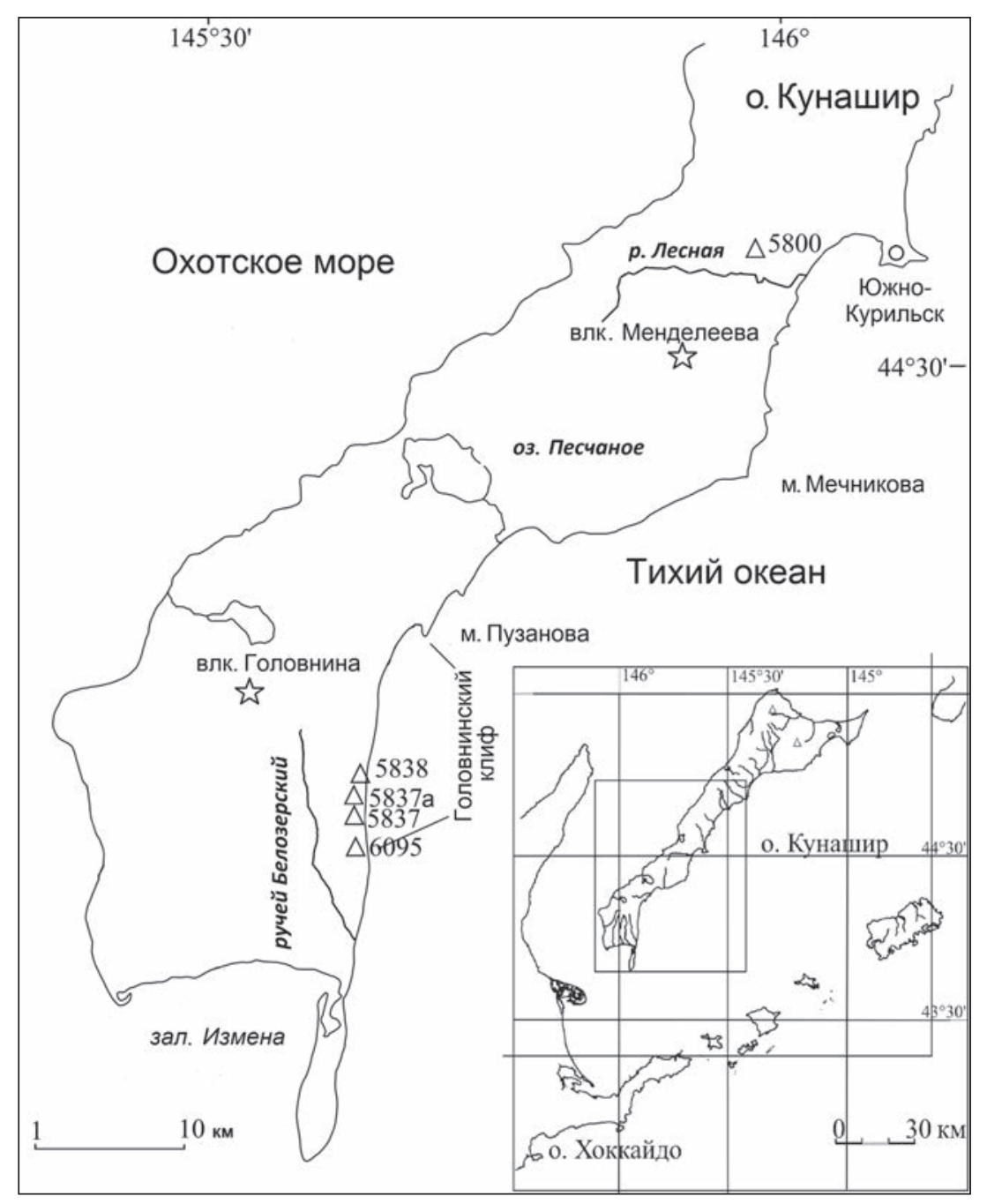

Puc. 1. Схема расположения изученных разрезов головнинской свиты Fig.1. Location scheme of the Golovnin suite sections studied 
В качестве возрастной модели применена 30нальная диатомовая шкала Северной Пацифики (Пушкарь и др., 2013; Pushkar et al., 2014) и кислородно-изотопная шкала LR04, построенная по фораминиферам (Lisiecki, Raymo, 2005). Видовая номенклатура диатомей дана по современным диатомовым базам Algaebase (http:/www. algaebase.org/search/species/).

Материалом для работы послужили образцы, отобранные в отложениях верхней части голостратотипа головнинской свиты (верхний плиоцен средний плейстоцен) о. Кунашир от м. Пузанова

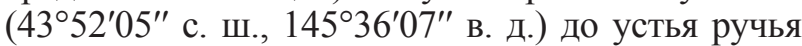

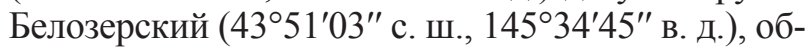
нажающиеся в Головнинском клифе, а также в карьере у подножья горы Отдельная по левому берегу р. Лесная $\left(44^{\circ} 00^{\prime} 57^{\prime \prime}\right.$ с. ш., $145^{\circ} 46^{\prime} 37^{\prime \prime}$ в. д.) (рис. 1).

\section{РЕЗУЛЬТАТЫ ИССЛЕДОВАНИЯ И ИХ ОБСУЖДЕНИЕ}

Верхняя подсвита (высота обнажений до 50 м) сложена моноклинально залегающими (азимут падения 80-90, угол падения 5-10) туфоалевритами, туфодиатомитами, песками и алевритами, переслаивающимися с пепловыми прослоями и пачками тефроидов, что позволяло отбирать пробы и у подножия клифа (рис. 2). Перекрывается подсвита аллювиально-озерными отложениями белозерских слоев верхнего плейстоцена $\left(\mathrm{alQ}^{3}{ }_{\mathrm{III}}\right)$ и лимническими фациями голоцена $\left(1 \mathrm{mQ} \mathrm{Q}_{\mathrm{IV}}\right)$ (Пушкарь, Разжигаева, 2003).

Литостратиграфия. В отложениях верхней части головнинской свиты выделено пять литологических пачек:

пачка 1 (mQII, разрез 5838 и вдоль основания клифа, мощность до 45 м) представлена пересла иванием алевритов и мелкозернистого песка с пемзовой галькой. Венчает кровлю пачки туфоалеврит мощностью до 2 м; пачка 2 (mQII, разрез 5837а по основанию клифа, мощность до 25 м) согласно залегает на отложениях пачки 1. Состоит из мелкозернистых песков с раковинами морских моллюсков в основании. В нижней части пачки прослеживаются четыре слоя риолитового пепла $\left(\mathrm{SiO}_{2}-70.66\right.$ $73.73 \%$ ) толщиной 5-7 см - Kbl-II-5, 6, 7, 8;

пачка 3 (vlQII, мощность до 16 м) согласно перекрывает отложения пачки 2 и представлена пемзовым туфом (Kbl-II-4). В нижней части пачки обильна хорошо окатанная галька дацитового состава $\left(\mathrm{SiO}_{2}-66.96, \mathrm{~K}_{2} \mathrm{O}-0.58 \%\right)$;

пачка 4 (mQII, мощность до 6 м) несогласно перекрывает плиоценовые туфы и отложения пачек 2 и 3 (разрезы 5837, 6095) и сложена мелкозернистым песком с галькой, переходящим к югу клифа в илистый песок. В подошве и кровле пачки лежат два слоя вулканического пепла дацитриолитового состава Kbl-II-3 и Kbl-II-2 (толщина 0.5 м и 0.25 м);

пачка 5 (vlQII, мощность до 20 м, разрезы 5837 и 6095) согласно перекрывает отложения пачки 4 и состоит из пемзового туфа Kbl-II-1 ( $\mathrm{SiO}_{2}$ $1.99 \%)$ с низким содержанием $\mathrm{K}_{2} \mathrm{O}(0.49-0.66 \%)$.

Возрастная модель. По комплексу вымерших диатомей в среднем плейстоцене (Пушкарь, Разжигаева, 2003). (Thalassiosira gravida Cleve var. fossilis Jousé, Th. nidulus (Tempere et Brun) Jousé var. nidulus, Th. jouseae Akiba, Actinocyclus ochotensis var. fossilis Pushkar, Proboscia curvirostris (Jousé) Jordan et Priddle, Stephanopyxis (Pyxidicula) dimorpha Schrader и встречаемости зонального вида Proboscia barboi (Brun) Jordan et Priddle изученные отложения относятся к диатомовой зоне Proboscia barboi с возрастом 0.55-0.28 млн лет (Пушкарь и др., 2013; Pushkar et al., 2014). Корректировать возраст позволяет комплекс силикофлагеллят Paradictyocha polyactis (Ehr.) Freng. f. completa Freng., Distephanus speculum (Ehr.) Haeckel var. speculum, D. speculum

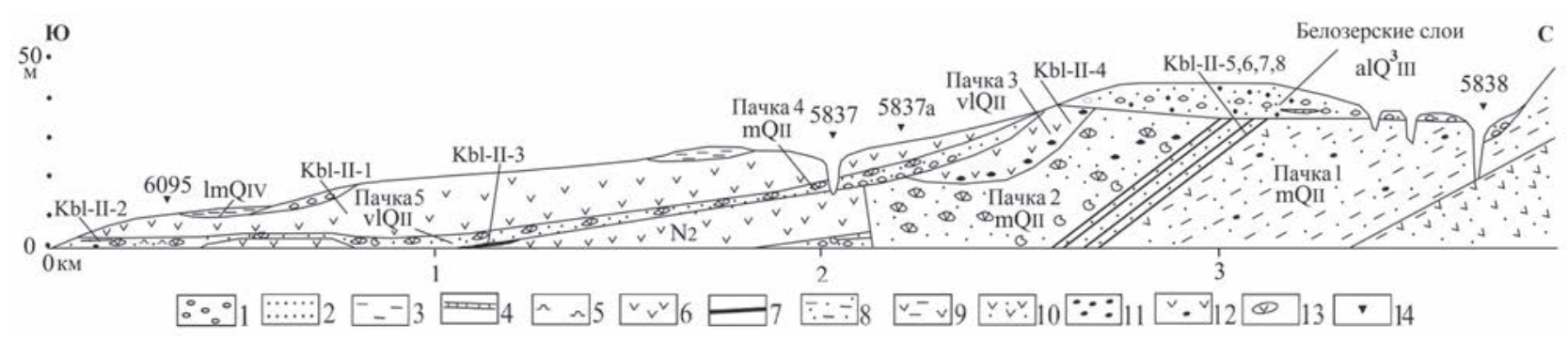

Puс. 2. Строение и состав верхней части головнинской свиты о. Кунашир (по: Пушкарь, Разжигаева, 2003, с небольшими изменениями): 1 - галька; 2 - песок; 3 - алеврит; 4 - торф; 5 - диатомит; 6 - туф; 7 - вулканический пепел; 8 - алеврит песчанистый; 9 - туфоалеврит; 10 - туфопесчаник; 11 - пемзовая галька; 12 - пемзовый туф; 13 - вулканическая бомба; 14 - разрезы

Fig. 2. Structure and composition of the Golovnin suite upper part, Kunashir Island (after Pushkar, Razzhigaeva, 2003, with minor changes): 1 - pebbles; 2 - sand; 3 -silt; 4 - peat; 5 -diatomite; 6 - tuff; 7 - volcanic ash; 8 - sandy silt; 9 - tuffaceous silt; 10 - tuffaceous sandstone; 11 - pumice pebbles; 12 - pumice tuff; 13 - volcanic bomb; 14 sections 
var. septenarius (Ehr.) Jorg., D. octonarius (Ehr.) Defl. var. polyactis (Jorg.) Gleser и Dictyocha fibula (Ehr.) var. fibula (в сумме 7\%), встреченных в отложениях нижней части разреза 5800 (13.06.7 м). Это указывает на их формирование в пределах миндель-рисского межледниковья (424374 тыс. л. н., МИС-11). Установлено также, что прослой Kbl-II-8 с высоким содержанием K 2 O является региональным маркером среднего плейстоцена (Пушкарь, Разжигаева, 2003).

Биостратиграфия. Наиболее полно комплексы диатомей изучены в отложениях разреза 5800 (рис. 3).

В его основании (13-9.8 м от его подошвы) выходит пачка туфодиатомитов $\left(\mathrm{SiO}_{2 \text { аморф. }}-74.3 \%\right)$. Средняя часть разреза $(9.8-5.0$ м) сложена тефрогенными алевритами $\left(\mathrm{SiO}_{2 \text { аморф. }}-18.96 \%\right)$ с риолитовыми пепловыми прослоями толщиной до 4 см. Верхняя часть (1-5 м) представлена переслаиванием алевритов и песков с пемзой и прослоями дацитовых пеплов, толщина до 1-2 см $\left(\mathrm{K}_{\mathrm{yk}}-\mathrm{II}\right)$. Кровля разреза характеризуется супе- сью и почвой (1-0 м). Пепловые прослои по химическому составу сопоставимы с пепловыми прослоями разрезов Головнинского клифа (пеплы Kbl-II), что послужило основанием прямой корреляции комплексов диатомей разреза 5800 с комплексами пачек Головнинского клифа.

Комплекс I (13.0-9.8 м). Доминируют планктонные Actinocyclus curvatulus Janisch (10.7\%), A. divisus (Grunow) Hustedt (19\%), а из сублиторальных обильны северо-бореальный Delphineis kippae Sancetta (12.3\%) и южно-бореальный Hyalodiscus obsoletus Sheshukova-Poretskaya (33\%). В отложениях встречены силикофлагелляты Paradictyocha polyactis (Ehr.) Freng. f. completa Freng., Distephanus speculum (Ehr.) Haeckel var. speculum, D. speculum var. septenarius (Ehr.) Jorg., D. octonarius (Ehr.) Defl. var. polyactis (Jorg.) Gleser и Dictyocha fibula (Ehr.) var. fibula (в сумме 7\%). Важной чертой комплекса является высокая встречаемость южнобореальных и субтропических океанических диатомей Coscinodiscus asteromphalus Ehr., C.

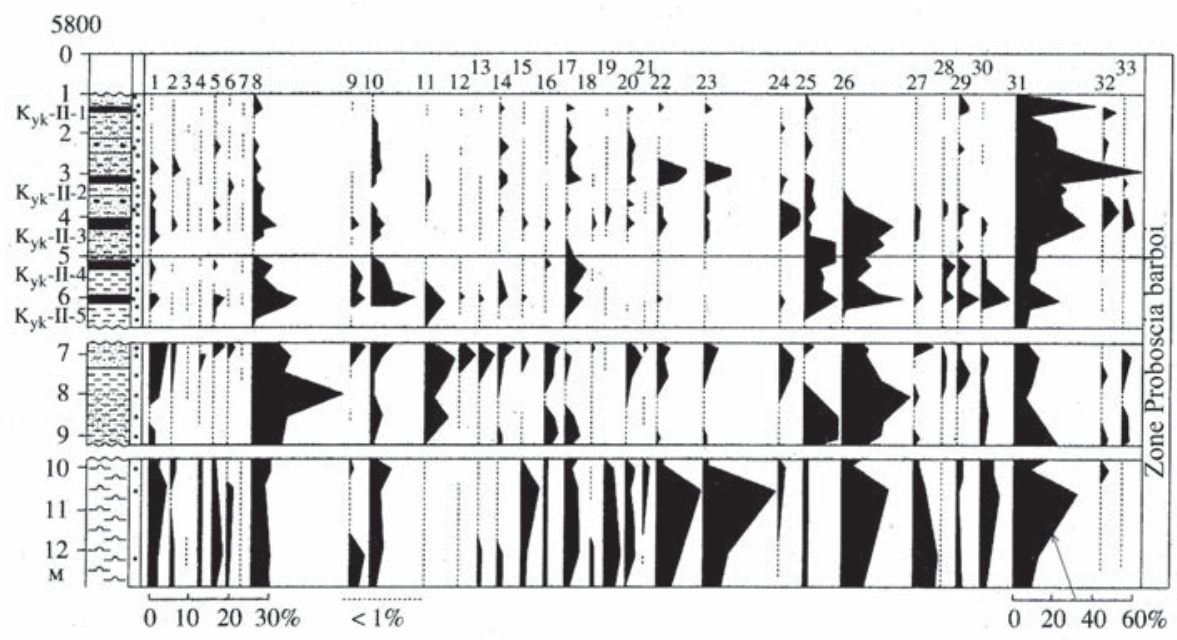

Puc. 3. Распределение диатомей в отложениях разреза 5800:

Fig. 3. Diatom distribution in the deposits of Section 5800:

группа 1 (Group 1) - зональные виды-индексы Proboscia barboi Zone (zonal index-species of Proboscia barboi Zone): 1 - Thalassiosira gravida var. fossilis Jousé; 2 - Th. nidulus (Temp. et Brun.) Jousé var. nidulus; 3 - Th. jouseae Akiba; 4 -Actinocyclus ochotensis var. fossilis Pushkar; 5 - Proboscia curvirostris (Jousé) Jordan et Priddle; 6 - P. barboi (Brun.) Jordan et Priddle; 7 - Stephanopyxis dimorpha Schrader; группа 2 (Group 2) - океанические и неритические аркто- и северо-бореальные виды (оceanic and neritic arctic- and north-boreal species): 8 - Thalassiosira gravida Cl. var. gravid; 9 - Th. hyalina (Grun.) Gran; 10 - Th. eccentrica (Ehr.) Cl.; 11 - Th. kryophila (Grun.) Jorg.; 12 - Th. antarctica Comber; 13 - Th. nordenskioeldii Cl.; 14 - Porosira glacialis (Grun.) Jorg.; 15 - Coscinodiscus marginatus Ehr. var. marginatus; 16 - Odontella aurita (Lyngb.) Ag.; 17 - Chaetoceros sp. sp. (spores); 18 - Neodenticula seminae (Sim. et Kanaya) Akiba et Yanagisawa; группа 3 (Group 3) - океанические и неритические южно-бореальные и субтропические виды (oceanic and neritic south- and subtropical species): 19 - Coscinodiscus asteromphalus Ehr. var. asteromphalus; 20 - C. radiatus Ehr.+C. perforatus Ehr.; 21 - Azpeitia nodulifera (A. S.) Fryxell et Sims; 22 - Actinocyclus curvatulus Jan.; 23 - A. divisus (Grun.) Hust.; 24 - Actinoptychus senarius (Ehr.) Ehr.; группа 4 (Group 4) - сублиторальные бентические и тихопелагические аркто- и северо-бореальные виды (sublittoral benthic and tychopelagic species) : 25 - Paralia sulcata (Ehr.) Cl. var. sulcata; 26 - Delphineis kippae Sancetta; 27 - Grammatophora oceanica Ehr. var. oceanica; 28 - Trachyneis aspera (Ehr.) Cl. var. aspera; 29 - Diploneis smithii (Bréb.) Cl. var. smithii; 30 - Cocconeis scutellum Ehr. var. scutellum; группа 5 (Group 5) - сублиторальные бентические южно-бореальные виды (sublithoral benthic south-boreal species: 31 - Hyalodiscus obsoletus Sheshuk.; 32 -Arachnoidiscus ehrenbergii Bail.; 33 - Petroneis marina (Ralfs) Crawford et Mann+Lyrella lyra (Ehr.) Karayeva var. lyra. 1\%=3 створок диатомей (diatom valves) 
radiatus Ehr. и C. perforatus Ehr. (в сумме до $47.5 \%$ ). Абсолютная численность створок диатомей в 1 г осадка достигает 20 млн.

Комплекс II (9.8-6.7 м). Вымершие виды составляют $6.7 \%$. Среди аркто- и северо-бореальных диатомей доминируют неритические виды Thalassiosira gravida Cleve var. gravida (24\%), Th. kryophila (Grunow) Jorgensen (7.7\%), а среди сублиторальных - северо-бореальные Paralia sulcata (Ehr.) Cleve (9\%) и Delphineis kippae Sancetta (17\%), а также южно-бореальный Hyalodiscus obsoletus Sheshukova-Poretskaya (21\%). Абсолютная численность створок диатомей в 1 г осадка составляет 10-16 млн.

Комплекс III (6.7-5.0 м). Вымершие виды сохраняют численность 1-2\%. Структуру формируют неритические холодноводные Thalassiosira gravida Cleve var. gravida (11.7\%), Th. kryophila ( 5\%) (Grunow) Jorgensen, широкобореальная Th. eccentrica (Ehr.) Cleve (12.2\%) и Chaetoceros spp. $(6.3 \%)$ (споры). Сублиторальная группа представлена Paralia sulcata (Ehr.) Cleve var. sulcata (8.3\%), Delphineis kippae Sancetta (15,3\%), Hyalodiscus obsoletus Sheshukova-Poretskaya (21.6\%). Абсолютная численность створок в 1 г осадка варьирует от 0.2 до 7 млн.
Комплекс IV (5.0-1.0 м). Вымерших видов около $2 \%$. Доминируют сублиторальный южнобореальный Hyalodiscus obsoletus SheshukovaPoretskaya (36-72\%), северо-бореальные Paralia sulcata (Ehr.) Cleve (18\%), Delphineis kippae Sancetta (12.7\%), а также океанические южнобореальные и субтропические Actinocyclus divisus Grun.) Hustedt (8\%), Coscinodiscus asteromphalus Ehr. (2.5\%), C. radiatus Ehr. и C. perforatus Ehr. (до 2.7\%). Встречен и тропический вид Azpeitia nodulifera (A. Sm.) G. A. Fryxell et Sims (2.2\%). Из группы 2 заметны планктонные Thalassiosira gravida Cleve var. gravida $(11.1 \%)$ и Асtinocyclus curvatulus Janisch (7.3\%). Абсолютная численность диатомей в 1 г осадка достигает 15 млн. Встречены и силикофлагелляты Paradictyocha polyactis (Ehr.) Freng. f. completa Freng., Distephanus speculum (Ehr.) Haeckel var. speculum, D. speculum var. septenarius (Ehr.) Jorg., D. octonarius (Ehr.) Defl. var. polyactis (Jorg.) Gleser и Dictyocha fibula (Ehr.) var. fibula (до 7\%).

В голостратотипе головнинской свиты диатомеи не столь обильны, как в отложениях разреза 5800, из-за участия в отложениях пирогенного материала, влияющего на концентрацию диатомей (до 3-4 млн створок в 1 г осадка). Лишь

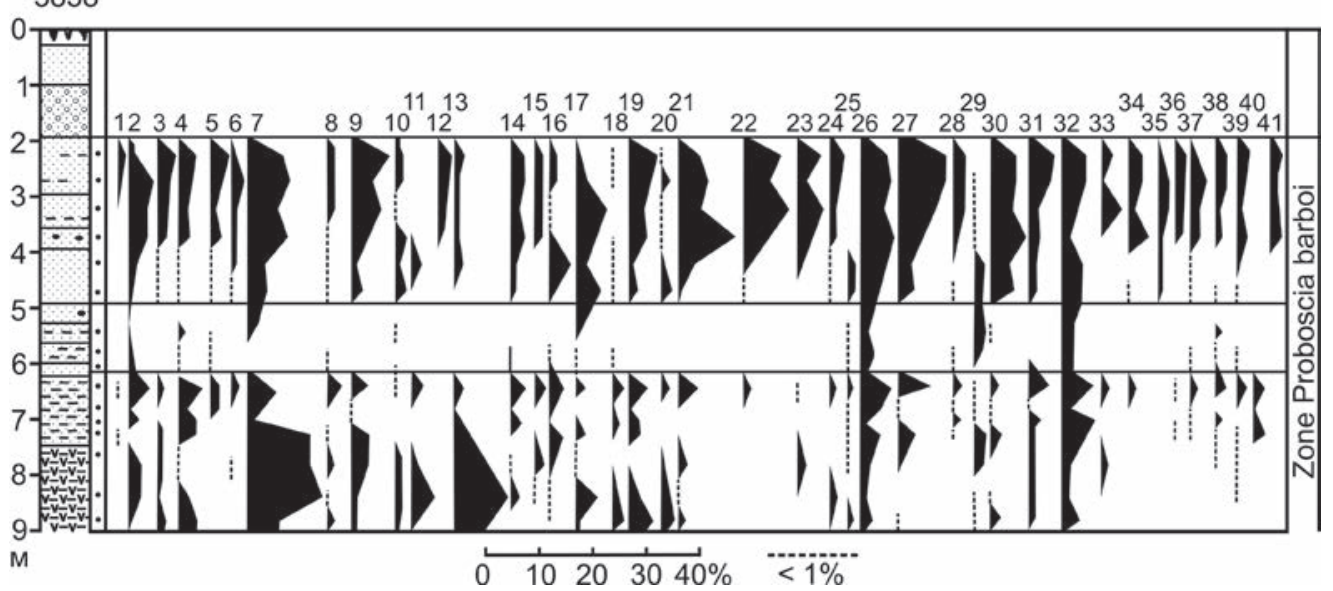

Puc. 4. Распределение диатомей в отложениях разреза 5838 (группы, как и в рис. 3):

Fig. 4. Diatom distribution in the deposits of Section 5838 (groups are the same as in Fig. 3):

группа 1 (Group 1): 1 - Stephanopyxis dimorpha Schrader; 2 - Thalassiosira gravida var. fossilis Jousé; 3 - Th. nidulus var. nidulus Jousé; 4 - Proboscia curvirostris (Jousé) Jordan et Priddle; 5 - P. barboi (Brun.) Jordan et Priddle; 6 - Actinocyclus ochotensis var. fossilis Pushkar; группа 2 (Group 2): 7 - Thalassiosira gravida Cl. var. gravid; 8 - Th. hyalina (Grun.) Gran; 9 - Th. eccentrica (Ehr.) Cl.; 10 - Th. kryophila (Grun.) Jorg.; 11 - Th. antarctica Comber; 12 Th. nordenskioeldii Cl.; 13 - Bacterosira bathyomphala (Cl.) Syvertsen et Hasle; 14 - Coscinodiscus marginatus Ehr. var. marginatus; 15 - Coscinodiscus oculus-iridis Ehr.; 16 - Chaetoceros sp. sp. (spores); 17 - Rhizosolenia hebetata Bail.; 18 - Thalassiothrix longissima Cl. et Grun.; 19 - Neodenticula seminae (Sim. et Kanaya) Akiba et Yanagisawa; грyппа 3 (Group 3): 20 - Shionodiscus latimarginatus (Makarova) Alverson, Kang et Theriot; 21 - Coscinodiscus asteromphalus Ehr. var. asteromphalus; 22 - C. radiatus Ehr.+C. perforatus Ehr.; 23 - Actinocyclus divisus (Grun) Hust.; 24 - Thalassionema nitzschioides (Grun.) Mer.; 25 - Rhizosolenia styliformis Bright.; группа 4 (Group 4): 26 - Paralia sulcata (Ehr.) Cl. var. sulcata; 27 - Delphineis kippae Sancetta; 28 - Grammatophora oceanica Ehr. var. oceanica; 29 - Navicula distans (W. Sm.) Ralfs; 30 - Trachyneis aspera (Ehr.) Cl. var. aspera; 31 - Diploneis smithii (Bréb.) Cl. var. smithii; 32 D. smithii (Bréb.) Cl. var. smithii $+D$. interrupta (Kütz.) Cl.; группа 5 (Group 5): 33 - Cyclotella striata (Kütz.) Grun. var. striata; 34 - Actinoptychus senarius (Ehr.) Ehr.; 35 - Aulacodiscus affinis Grun.; 36 - Petroneis marina (Ralfs) Crawford et Mann; 37 - Lyrella hennedyi (W. Sm.) Stickle et Mann; 38 - Diploneis crabro Ehr. var. crabro; 39 - D. weissflogii (A. S.) Cl.; 40 - Achnanthes brevipes var. intermedia (Kütz.) Cl.; 41 - Nitzschia angularis W. Sm. var. angularis 
только отложения разрезов 5838 и 6095 содержат до 10-15 млн створок в 1 г осадка.

В разрезе 5838 (пачка 1, рис. 4) встречены те же вымершие диатомеи и силикофлагелляты, что и в разрезе 5800. В нижней части (9.10-7.8 м от кровли) доминируют неритические Thalassiosira gravida Cleve var. gravida (14\%) и Bacterosira fragilis (Gran) Gran (Bacterosira bathyomphala (Cleve) Syvertsen et Hasle) (10\%). В средней части разреза (7.8-5.0 м) диатомеи редки, а в верхней (5.0-2.0 м) значительная роль принадлежит стеногалинному планктону - Coscinodiscus asteromphalus Ehr. var. asteromphalus $(15.6 \%)$, C. radiatus Ehr. + C. perforatus Ehr. (17.2\%), Зональный вид Proboscia. barboi (Brun) Jordan et Priddle достигает численности 1.5-2\%. Верхний комплекс диатомей хорошо коррелируется с комплексом 1 разреза 5800.

В разрезе пачки 2 (5837a, см. рис. 2) Головнинского клифа диатомеи редки (0.2-2.5 млн створок в 1 г осадка) и представлены в основном сублиторальными диатомеями $(82.7 \%)$, среди которых доминируют холодноводные сублиторальные Paralia sulcata var. sulcata (Ehr.) Cleve и Paralia sulcata var. biseriata Grunow (до 38\%). Встречены и пресноводные диатомеи родов Navicula Bory, Pinnularia Ehr., Aulacoseira Thwaites, Achnanthes Bory (12.8\%). Отложения пачки 3 (пемзовый туф) диатомей не содержат.

Отложения пачки 4 изучены в разрезах 5837 и 6095. В разрезе 5837 (рис. 5) вымершие диатомеи в отложениях единичны. Только Proboscia barboi (Brun) Jordan et Priddle достигает 2\%. Доминантами комплекса (9.5-6.6 м от поверхности клифа) являются сублиторальные Paralia sulcata var. sulcata (Ehr.) Cleve и Paralia sulcata var. biseriata Grunow (в сумме до 86.8\%). Встречены и умеренно-тепловодные сублиторальные Нуаlodiscus obsoletus Sheshukova-Poretskaya, Lyrella lyra (Ehr.) Karajeva, Actinocyclus octonarius Ehr., Arachnoidiscus ehrenbergii Ralfs (в сумме до $20 \%$ ), и океанические Actinocyclus curvatulus Janish, Coscinodiscus radiatus Ehr. (в сумме до 7.5\%). Выше по разрезу диатомеи очень редки.

В разрезе 6095 комплекс диатомей характеризуется высокой значимостью двух вымерших видов Proboscia: P. curvirostris (Jousé) Jordan et Priddle (12.5\%) и P. barboi (Brun) Jordan et Priddle (7.5\%). В его экологической структуре комплекса важную роль играют тропические и субтро-

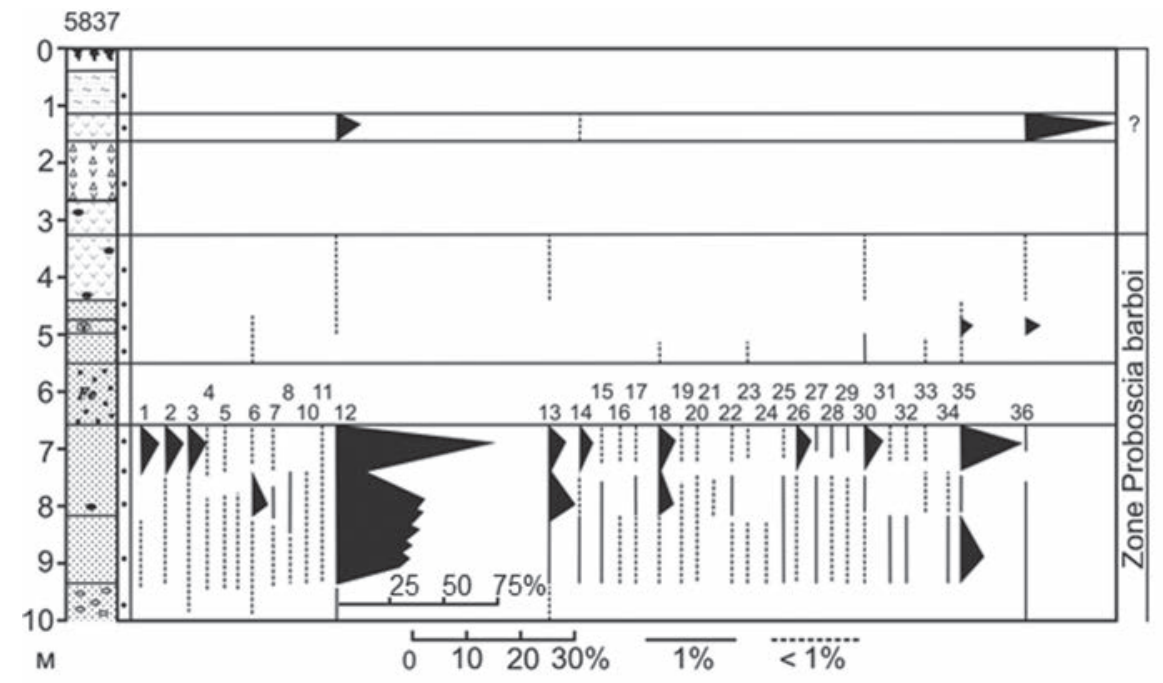

Puc. 5. Распределение диатомей в отложениях разреза 5837:

Fig. 5. Diatom distribution in the deposits of section 5837:

1 - Stephanopyxis turris (Grev.) Ralfs ex Pritchard var. turris; 2 - S. nipponica Gran et Yendo; 3 - Thalassiosira gravida Cl. var. gravid; 4 - Th. gravida var. fossilis Jousé; 5 - Th. nidulus var. nidulus Jousé; 6 - Th. jouseae Akiba; 7 - Th. eccentrica (Ehr.) Cl.; 8 - Th. pacifica Gran et Angst; 9 - Shionodiscus latimarginatus (Makarova) Alverson, Kang et Theriot; 10 - Porosira glacialis (Grun.) Jorg.; 11 - Bacterosira bathyomphala (Cl.) Syvertsen et Hasle; 12 Paralia sulcata var. biseriata Grun.; 13 - Hyalodiscus obsoletus Sheshuk.; 14 - Coscinodiscus marginatus Ehr. var. marginatus; 15 - Coscinodiscus radiatus Ehr.; 16 - Actinocyclus ochotensis var. fossilis Pushkar; 17 - A. curvatulus Jan.; 18 - A. divisus (Grun.) Hust.; 19 - Arachnoidiscus ehrenbergii Bail.; 20 - Actinoptychus senarius (Ehr.) Ehr.; 21 - Actinoptychus undulatus var. tamanica Jousé; 22 - Actinocyclus octonarius Ehr.; 23 - Odontella aurita (Lyngb.) Ag.; 24 - Chaetoceros compressus Laud.; 25 - Proboscia curvirostris (Jousé) Jordan et Priddle; 26 - P. barboi (Brun.) Jordan et Priddle; 27 - Rhaphoneis amphiceros (Ehr.) Ehr. var. amphiceros; 28 - Delphineis kippae Sancetta; 29 Rhabdonema arcuatum (Lyngb.) Kütz. var. arcuatum; 30 - Grammatophora oceanica Ehr. var. oceanica; 31 - Lyrella lyra (Ehr.) Karayeva; 32 - Trachyneis aspera (Ehr.) Cl. var. aspera; 33 - Cocconeis costata Greg. var. costata; 34 - C. vitrea Brun; 35 - переотложенные неогеновые диатомеи (redeposited Neogene diatoms); 36 - пресноводные диатомеи (freshwater diatoms) 
пические диатомеи ( в сумме до 29.8\%): Azpeitia nodulifera (A. Schmidt) G. A. Fryxell et P. A. Sims, Thalassiosira lineata Jousé, Shionodiscus oestrupii (Ostenfeld) A. J. Alverson, S.-H. Kang \& E. C. Theriot), Coscinodiscus asteromphalus Ehr., C. radiatus Ehr. и C. perforatus Ehr. Абсолютная численность створок диатомей в 1 г осадка достигает 15 млн. Комплекс отражает более глубоководные отложения, чем одновозрастный комплекс разреза 5837.

Палеогеографическая интерпретация. Формирование среднеплейстоценовых толщ острова Кунашир сопровождалось сильными выбросами пирокластики. Активная вулканическая деятельность происходила синхронно с вулканами о. Хоккайдо и обусловила высокие скорости седиментации, что способствовало формированию мощных вулканогенно-осадочных толщ, запечатлевших в себе как этапы вулканической активности, так и палеоклиматические изменения и колебания уровня моря (Пушкарь, Разжигаева, 1998; Pushkar, Razjigaeva, 2003).

Согласно возрастной модели выделенные комплексы диатомей укладываются во временной диапазон 11-9 МИС зоны Proboscia barboi. Комплексы, соответствующие МИС-11, установлены в разрезах 5800 и 5838. Для них характерно присутствие зональных вымерших видов (6-7\%) и морских планктонных субтропических и тропических диатомей (43-51\%). Если учесть, что современные ассоциации диатомей в этом тихоокеанском регионе содержат 17\% тепловодных видов (среднегодовая температура поверхностных вод составляет $7^{\circ} \mathrm{C}$ ), то следует допустить, что среднегодовая температура вод времени формирования отложений МИС-11 была на $8-10^{\circ} \mathrm{C}$ выше современной. Отложения средней части разреза (комплекс III) характеризуются падением численности тепловодных диатомей и снижением количества створок в 1 г осадка до 0-0.2 тыс. створок, что указывает на похолодание климата и свидетельствует о колебании палеоклиматических параметров в течение самой МИС-11, что соответствует и глобальной климатической ритмике (Lisiecki, Raymo, 2005). Аналогичные изменения комплексов отражены в отложениях пачки 1 разреза 5838, имеющие хорошую корреляцию по вулканическим пепловым прослоям с отложениями разреза 5800 (Пушкарь, Разжигаева, 2003).

Отложения пачек 2-3 содержат бентические и тихопелагические диатомеи $(82.7 \%)$, среди которых доминируют холодноводные сублиторальные Paralia sulcata var. sulcata (Ehr.) Cleve и Paralia sulcata var. biseriata Grunow (до 38\%), и свидетельствуют о холодных климатических условиях на фоне регрессии моря. О близости береговой линии свидетельствуют пресноводные диато- меи (12.8\%). По-видимому, эти комплексы соответствуют стадии МИС-10 (374-330 тыс. л. н.).

Диатомовый комплекс пачки 4 (разрез 5837 и 6095) отражает новую волну потепления и сопоставляется с МИС-9. Судя по участию тепловодных диатомей (29.8\%), температура поверхностных водных масс в районе формирования осадков могла быть выше современной на 3-5․

В разрезе 5800 зафиксирована трансгрессивная серия отложений МИС-11. Судя по экологической структуре комплекса (свыше 50\% неритических и океанических видов), подобные комплексы уже начинают формироваться на глубинах около 50 м. Такая же ситуация отмечается и для комплекса диатомей разреза 5838. Кровля пачки 1 лежит на высоте 50 м. Если учитывать тектонический подъем океанического берега о. Кунашир в 0.3 мм в год (Пушкарь, Разжигаева, 1998, 2003), то глубина формирования отложений МИС-11 должна была составлять около 70 м. Следовательно, можно предположить, что уровень моря 400 тыс. л. н. был не менее чем на +20 м выше современного.

Отложения разреза 5837 содержат сублиторальный бентический комплекс диатомей (91.5\%) с абсолютным доминированием Paralia sulcata var. sulcata (Ehr.) Cleve и Paralia sulcata var. biseriata Grunow (в сумме до 86.8\%). Можно предположить, что такая экологическая структура могла формироваться пределах мелководного шельфа на глубинах около или менее 20 м, на которых в области песчаных мелководий расположена оптимальная экологическая ниша этих видов (McQuoid, Hobson, 1998; McQuoid et al., 2007; Gebühr et al., 2009; Пушкарь и др., 2019). В этом случае трансгрессия не была столь значительной, как во время МИС-11. Учитывая высотное расположение разреза 5837, скорость и время формирования отложений МИС-9, можно предположить, что уровень моря, вероятно, не превышал +5 м по отношению к современному.

Одновозрастный комплекс разреза 6095 формировался в более глубоких зонах шельфа, и отложения, его содержащие, расположены на отметке современной береговой линии.

\section{ЗАКЛЮЧЕНИЕ}

MIS-11 является необычайно длинным межледниковым терминальным периодом, характеризующимся слабыми орбитальными изменениями и, соответственно, распределением солнечной инсоляции. Но комплексы диатомей отложений МИС-11 отражают достаточно высокие среднегодовые температуры поверхностных вод (выше современных на $+10^{\circ} \mathrm{C}$ ), следовательно, была и другая причина, повлиявшая на столь теплые климатические условия и высокое положение береговых линий за счет изменения объ- 
ема вод Мирового океана в результате коллапсирующего таяния ледниковых покровов планеты. Иная климатическая ситуация отражена в диатомовых комплексах отложений МИС-9, причиной которой были именно инсоляционные изменения, связанные с орбитальными параметрами. Различия в палеоклиматическом режиме и положении береговых линий между двумя стадиями, по-видимому, связаны с влиянием концентрации $\mathrm{CO}_{2}$, обеспечивающей парниковый эффект. Но глобальные углеродные циклы, скорее всего, имеют собственную реакцию на изменения орбитального характера и собственную историю, которая не вызвана ледниковой периодичностью как первопричиной. Вполне допустимо, что изменение палеопродуктивности диатомовых водорослей как фотосинтетиков может соответствовать этим углеродным циклам, а изменение концентрации створок диатомей в отложениях Мирового океана может служить одним из критериев для определения относительных изменений $\mathrm{CO}_{2}$ в атмосфере геологического прошлого.

\section{ЛИТЕРАТУРА}

Большаков В. А. Проблема межледниковой 11-й морской изотопной стадии с позиций новой концепции орбитальной теории палеоклимата // Океанология. 2010. Т. 50, № 2. С. 236-247.

Большаков B. A. Связь глобальных колебаний климата в плейстоцене с вариациями орбитальных параметров Земли // Стратиграфия. Геологическая корреляция. 2014. Т. 22, № 5. С. 97-112.

Ложкин А. В., Андерсон П. М., Матросова Т. В. Минюк П. С., Бригхем-Гретте Дж., Меллес М. Непрерывная летопись изменений природной среды Чукотки за последние 350 тыс. лет // Тихоокеанская геология. 2007. Т. 26, № 6. С. 53-59.

Ложкин А. В., Андерсон П. М., Минюк П. С., Недоpубова Е. Ю. Смена биоценозов в Восточной Арктике 374-917 тыс. лет назад (по данным палинологического анализа осадков озера Эльгыгытгын) // Вестник СВНЦ ДВО РАН. 2016. № 2. С. 3-9.

Недорубова Е. Ю. Природная среда Чукотки 360 430 тыс. лет назад (по данным палинологического исследования осадков оз. Эльгыгытгын) // Там же. 2014. № 4. С. 29-33.

Недорубова Е. Ю. Межледниковья и ледниковые стадии среднего плейстоцена в пыльцевой записи оз. Эльгыгытгын (Центральная Чукотка) // Там же. 2018. № 1. C. 32-38

Пушкарь В. С., Разжигаева Н. Г. Головнинская свита плиоцена - плейстоцена о. Кунашир (Курилы): стратиграфия и условия формирования // Стратиграфия. Геол. корреляция. 2003. Т. 11, № 5. С. $82-$ 94.

Пушкарь В. С., Черепанова М. В. Диатомеи плиоцена и антропогена Северной Пацифики. Владивосток : Дальнаука, 2001. 228 с.

Пушкарь В. С., Черепанова М. В. Диатомовые комплексы и корреляция четвертичных отложений северо-западной части Тихого океана. Владивосток : Дальнаука, 2008. 174 с.
Пушкарь В. С., Разжигаева Н. Г., Короткий А. М., Мохова Л. М. Позднеголовнинская трансгрессия среднего плейстоцена на о. Кунашир (Курильские острова) // Стратиграфия. Геол. корреляция. 1998. Т. 6, № 6. C. 52-63.

Пушкарь В. С., Черепанова М. В., Лихачева О. Ю. Совершенствование зональной диатомовой шкалы плиоцена и квартера Северной Пацифики // Тихоокеанская геология. 2013. Т. 32, № 5. С. 52-66.

Пушкарь В. С., Черепанова М. В., Тарасова Е. В. Климатические изменения времени МИС-5 Арктической Чукотки и Аляски // Вестник СВНЦ ДВО РАН. 2019. № 3. С. 27-36.

Bowen D. Q. Sea level 400000 years ago (MIS 11): analogue for present and future sea-level? // Climate of the Past. 2010. Vol. 6. P. 19-29. DOI: 10.5194/cp-6-192010

Caissie Beth E., Brigham-Grette J., Cook Mea S., Colmenero-Hidalgo Elena. Bering Sea surface water conditions during Marine Isotope Stage 12 to 10 at Navarin Canyon (IODP Site U1345) // Ibid. 2016. Vol. 12. P.17391763. DOI: $10.5194 / \mathrm{cp}-12-1739-2016$

D’Anjou R. M., Wei J. H., Castañeda I. S., BrighamGrette J., Petsch S. T., Finkelstein D. B. High-latitude environmental change during MIS 9 and 11: biogeochemical evidence from Lake El'gygytgyn, Far East Russia // Ibid. 2013. Vol. 9. P. 567-581. DOI: 10.5194/cp-9-5672013

Gebühr Cristina, Wiltshire Karen H., Aberle Nicole, van Beusekom Justus E. E., Gerdts Gunnar. Influence of nutrients, light and salinity on the occurrence of Paralia sulcata at Helgoland Roads, North Sea // International Journal of Aquatic Biology. 2009. 7. P. 185-197. DOI: 10.3354/ab00191

Hearty P. J. Comment on "Sea level 400000 years ago (MIS 11): analogue for present and future sea-level?" by D. Q. Bowen (2010). Can the extrapolation of uplift rates from MIS 5e shorelines to MIS 11 replace direct and tangible evidence of the latter's sea-level history? // Climate of the Past. 2010. Vol. 6. P. 295-305. DOI:10.5194/ cpd-6-295-2010

Hearty P. J., Kindler P., Cheng H., Edwards R. L. $\mathrm{A}+20 \mathrm{~m}$ Middle Pleistocene sea-level highstand (Bermuda and the Bahamas) due to partial collapse of Antarctic ice // Geology. 1999. Vol. 27, No. 4. P. 375-378.

Hearty Paul J., Olson Storrs. L. Mega-highstand or megatsunami? Discussion of McMurtry et al. (Elevated marine deposits in Bermuda record a late Quaternary megatsunami: Sedimentary Geology. 200 (2007) 155165) // Sedimentary Geology. 2008. Vol. 203. P. 307-312. DOI:10.1016/j.sedgeo.2007.08.001

Laukhin S. A., Jain Z., Pushkar V. S., Cherepanova $M$. $V$. Last glaciation in the northern part of the eastern Chukchi Peninsula and paleoceanography of the North Pacific // Doklady Earth Sciences. 2006. Vol. 411-A, No. 9. P. 1423-1426. DOI: 10.1134/S1028334X06090194

Lisiecki Lorraine E., Raymo Maureen E. A. PliocenePleistocene stack of 57 globally distributed benthic $\delta^{18} \mathrm{O}$ records // Paleoceanography. 2005. Vol. 20, No. (PA1003). P. 1-17. DOI: 10.1029/2004PA001071

Loutre M. F. Clues from MIS 11 to predict the future climate - a modeling point of view // Earth and Planetary Science Letters. 2003. Vol. 212. P. 213-224. DOI: $10.1016 / \mathrm{S} 0012-821 \mathrm{X}(03) 00235-8$ 
Lozhkin A. V., Anderson P. M. Vegetation responses to interglacial warming in the Arctic, examples from Lake El'gygytgyn, Far East Russian Arctic // Climate of the Past. 2013. Vol. 9. P. 1-23. DOI: 10.5194/cp-9-12112013

Lozhkin A. V., Anderson P. M., Matrosova T. V., Minyuk P. S., Brigham-Grette J., Melles M. The pollen records from El'gygytgyn Lake: implications for vegetation and climate histories of Northern Chukotka since the late Middle Pleistocene // Journal of Paleolimnology. 2007. Vol. 37, No. 1. P. 135-153. DOI: 10.1007/s10933006-9018-5

Lozhkin A. V., Minyuk P. S., Anderson P. M., Nedorubova E. Yu., Korzun J. V. Variability in landscape and lake system responses to glacial and interglacial climates during the Middle Pleistocene based on palynological and geochemical data from Lake El'gygytgyn, Eastern Arctic // Review of Palaeobotany and Palynology. 2017. Vol. 246. P. 1-13. DOI: 10.1007/s10933-006-9018-5

McMurtry David Gary, Tappin M. R., Sedwick Peter $N$., Wilkinson Ian, Fietzke Jan, Sellwood Bruce. Elevated marine deposits in Bermuda record a late Quaternary megatsunami // Sedimentary Geology. 2007. Vol. 200, No. 3-4. P. 155-165.

McQuoid M. R ., Hobson L. A. Assessment of palaeoenvironmental conditions on southern Vancouver Island, British Columbia, Canada, using the marine tychoplankter Paralia sulcata // Diatom Research. 1998. Vol. 13, No. 2. P. 311-321.

McQuoid M. R., Nordberg K. The diatom Paralia sulcata as an environmental indicator species in coastal sediments // Estuarine, Coastal and Shelf Science. 2003. Vol. 56, No. 2. P. 339-354. https://doi. org/10.1016/S0272-7714(02)00187-7

Melles M. 1., Brigham-Grette J., Minyuk P. S., Nowaczyk N. R., Wennrich V., DeConto R. M., Anderson P. M., Andreev A. A., Coletti A., Cook T. L., Haltia-Hovi E., Kukkonen M., Lozhkin A. V., Rosen P., Tarasov P. E., Vogel H., Wagner B. 2.8 Million years of Arctic climate change from Lake El'gygytgyn, NE Russia // Science. 2012. Vol. 337, No. 6092. P. 315-320. DOI: 10.1126/science. 1222135

Olson Storrs L., Hearty Paul J. A sustained $+21 \mathrm{~m}$ sea-level highstand during MIS 11 (400 ka): direct fossil and sedimentary evidence from Bermuda // Quaterna- ry Science Reviews. 2009. Vol. 28, No. 3-4. P. 271-285. https://doi.org/10.1016/j.quascirev.2008.11.001

Pushkar V. S., Cherepanova M. V. Beringia: Impact on paleoclimates on Northeast Asia and North Pacific during Last Pleistocene Glaciation // Quaternary International. 2011. Vol. 237. No. 1-2. P. 32-38. DOI:10.1016/j. quaint.2011.01.010

Pushkar V. S., Cherepanova M. V., Likhacheva O. Yu. Detalization of the Pliocene - Quaternary North Pacific Diatom Zonal Scale // International Journal on Algae, 2014. Vol. 16, No. 3. P. 284-306.

Pushkar V. S., Razjigaeva N. G. The Pliocene-Pleistocene Golovnin Formation of Kunashir Island (the Kuriles): Stratigraphy and Formation condition // Stratigraphy and Geological Correlation. 2003. Vol. 11, No. 5. P. 492-504.

Pushkar V. S., Roof S. R., Cherepanova M. V., Hopkins D. M., Brigham-Grette J. Paleogeographic and paleoclimatic significance of diatoms from Middle Pleistocene marine and glaciomarine deposits on Baldwin Peninsula, Northwestern Alaska // Palaeogeography, Palaeoclimatology, Palaeoecology. 1999. Vol. 152. P. 67-85.

Raymo Maureen E., Mitrovica Jerry X. Collapse of polar ice sheets during the stage 11 Interglacial // Nature. 2012. Vol. 483. P. 453-456. DOI: 10.1038/nature10891

Rohling E. J., Braun K., Grant K., Kucera M., Roberts A. P., Siddall M., Trommer G. Comparison between Holocene and Marine Isotope Stage-11 Sea-Level Histories // Earth and Planetary Science Letters. 2010. Vol. 291. P. 97-105. DOI: 10.1016/j.eps1.2009.12.054

Wennrich V., Minyuk P. S., Borkhodoev V. Ya., Francke A., Ritter B., Nowaczyk N. R., Sauerbrey M. A., BrighamGrette J., Melles M. Pliocene to Pleistocene climate and environmental history of Lake El'gygytgyn, Far East Russian Arctic, based on high-resolution inorganic geochemistry data // Climate of the Past. 2013. Vol. 9. P. 58995940. DOI: 10.5194/cpd-9-5899-2013

Yin Q. Z., Berger A. Insolation and $\mathrm{CO}_{2}$ contribution to the interglacial climate before and after the Mid-Brunhes Event // Nature Geoscience. 2010. Vol. 3, No. 4. P. 243 246. DOI: https://doi.org/10.1038/NGEO771

Yin $Q$., Berger $A$. Individual contribution of insolation and $\mathrm{CO}_{2}$ to the interglacial climates of the past 800.000 years // Climate Dynamics. 2012. Vol. 38. P. 709-724. DOI: $10.1007 / \mathrm{s} 00382-011-1013-5$

Поступила в редакциию 11.05.2020 2.

Поступила после доработки 25.05.2020 2.

\title{
CLIMATIC CHANGES DURING MIS-11-9, KUNASHIR ISLAND (Kuriles)
}

\section{V.S. Pushkar}

\author{
Far East Geological Institute, FEB RAS, Vladivostok
}

Middle Pleistocene sediments of the upper part of the Golovnin Formation, Kunashir Island (Kuril Islands), were formed during interglacial-glacial climatic and transgressive-regressive cycles, corresponding to marine isotopic stages (MIS) 11-9. During the MIS-11 transgression, the sea level was $20-25 \mathrm{~m}$ above the present, and to $5 \mathrm{~m}$ above the present during MIS-9. The tuff layers and depositional breaks correspond to the MIS-10 regression. The comparison of MIS-11 (424-374 kyr) and MIS-9 (337-300 kyr) paleoenvironments suggests that the warm climate and high sea levels during the long MIS-11 interglaciation were caused not only by orbit-induced changes in solar 
insolation. MIS 11 was the time of weak orbital changes in the distribution of solar insolation on the Earth surface. The environmental conditions of MIS-11 had other causes, probably associated with changes in the changing concentrations of the atmospheric carbon dioxide, reflected in the high photosynthetic paleoproductivity in diatoms.

\section{Keywords: climate, transgression, MIS-11-9, Interglacial, Middle Pleistocene, Kunashir Island, Kuril Islands.}

\section{REFERENCES}

Bol'shakov, V. A., 2010. The Problem of the Interglacial $11^{\text {th }}$ Marine Isotope Stage from the Perspective of a New Concept of the Orbital Theory of the Paleoclimate, Oceanology. 50, 2, 236-247 [In Russian].

Bol'shakov, V. A., 2014. Connection of Global Climate Fluctuations in the Pleistocene with Variations of the Earth's Orbital Parameters, Stratigraphy. Geological Correlation. 22, 5, 97-112 [In Russian]. DOI: 10.7868/ S0869592X14050044

Bowen, D. Q., 2010. Sea Level 400000 Years Ago (MIS 11): Analogue for Present and Future Sea-Level? Climate of the Past. 6, 19-29. DOI: 10.5194/cp-6-192010

Caissie, Beth E., Brigham-Grette, J., Cook, Mea S., Colmenero-Hidalgo, Elena, 2016. Bering Sea Surface Water Conditions during Marine Isotope Stage 12 to 10 at Navarin Canyon (IODP Site U1345), Ibid. 12, 17391763. DOI: $10.5194 / \mathrm{cp}-12-1739-2016$

D'Anjou, R. M., Wei, J. H., Castañeda, I. S., BrighamGrette, J., Petsch, S. T., Finkelstein, D. B., 2013. HighLatitude Environmental Change during MIS 9 and 11: Biogeochemical Evidence from Lake El'gygytgyn, Far East Russia, Ibid. 9, 567-581. DOI: 10.5194/cp-9-5672013

Gebühr, Cristina, Wiltshire, Karen H., Aberle, Nicole, van Beusekom, Justus, E. E., Gerdts, Gunnar, 2009. Influence of Nutrients, Light and Salinity on the Occurrence of Paralia sulcata at Helgoland Roads, North Sea, International Journal of Aquatic Biology. 7, 185197. DOI: $10.3354 / \mathrm{ab} 00191$

Hearty, P. J., 2010. Comment on "Sea Level 400000 Years Ago (MIS 11): Analogue for Present and Future SeaLevel?" by D. Q. Bowen (2010). Can the Extrapolation of Uplift Rates from MIS 5e Shorelines to MIS 11 Replace Direct and Tangible Evidence of the Latter's Sea-Level History? Climate of the Past. 6, 295-305. DOI:10.5194/ cpd-6-295-2010

Hearty, P. J., Kindler, P., Cheng, H., Edwards, R. L., 1999. A + 20 m Middle Pleistocene Sea-Level Highstand (Bermuda and the Bahamas) Due to Partial Collapse of Antarctic Ice, Geology. 27, 4, 375-378.

Hearty, Paul J., Olson, Storrs L., 2008. Mega-Hhighstand or Megatsunami? Discussion of McMurtry et al. (Elevated Marine Deposits in Bermuda Record a Late Quaternary Megatsunami: Sedimentary Geology. 200 (2007) 155-165), Sedimentary Geology. 203, 307-312. doi:10.1016/j.sedgeo.2007.08.001

Laukhin, S. A., Jain, Z., Pushkar, V. S., Cherepanova, M. V., 2006. Last Glaciation in the Northern Part of the Eastern Chukchi Peninsula and Paleoceanography of the North Pacific, Doklady Earth Sciences. 411-A, 9, 14231426. DOI: $10.1134 / \mathrm{S} 1028334 X 06090194$
Lisiecki, Lorraine E., Raymo, Maureen E. A., 2005. Pliocene-Pleistocene Stack of 57 Globally Distributed Benthic $\delta^{18} \mathrm{O}$ Records, Paleoceanography. 20, PA1003, 1-17. DOI: 10.1029/2004PA001071

Loutre, M. F., 2003. Clues from MIS 11 to Predict the Future Climate - a Modeling Point of View, Earth and Planetary Science Letters. 212, 213-224. DOI: 10.1016/ $\mathrm{S} 0012-821 \mathrm{X}(03) 00235-8$

Lozhkin, A. V., Anderson, P. M., 2013. Vegetation Responses to Interglacial Warming in the Arctic, Examples from Lake El'gygytgyn, Far East Russian Arctic, Climate of the Past. 9, 1-23. DOI: 10.5194/cp-9-1211-2013

Lozhkin, A. V., Anderson, P. M., Matrosova, T. V., Minyuk, P. S., Brigham-Grette, J., Melles, M., 2007. Continuous Chronicle of the Environment Changes of Chukotka Environment over the Past 350 Thousand Years, Russian Journal of Pacific Geology. 26, 6, 53-59 [In Russian].

Lozhkin, A. V., Anderson, P. M., Minyuk, P. S., Matrosova, T. V., 2016. Change of Biocenoses in the Eastern Arctic 374-917 Thousand Years Ago (According to Palynological Analysis of Sediments of Lake El'gygytgyn), Vestnik NESC FEB RAS. 2, 3-9 [In Russian].

Lozhkin, A. V., Anderson, P. M., Matrosova, T. V., Minyuk, P. S., 2007. The Pollen Records from El'gygytgyn Lake: Implications for Vegetation and Climate Histories of Northern Chukotka Since the Late Middle Pleistocene, Journal of Paleolimnology. 37, 1, 135-153. DOI: 10.1007/s10933-006-9018-5

Lozhkin, A. V., Minyuk, P. S., Anderson, P. M., Nedorubova, E. Yu., Korzun, J. V., 2017. Variability in Landscape and Lake System Responses to Glacial and Interglacial Climates during the Middle Pleistocene Based on Palynological and Geochemical Data from Lake El'gygytgyn, Eastern Arctic, Review of Palaeobotany and Palynology. 246, 1-13. DOI: 10.1007/s10933-006-9018-5

McMurtry, David Gary, Tappin, M. R., Sedwick, Peter N., Wilkinson, Ian, Fietzke, Jan, Sellwood, Bruce, 2007. Elevated Marine Deposits in Bermuda Record a Late Quaternary Megatsunami, Sedimentary Geology. 200, 3-4, 155-165.

McQuoid, M. R., Hobson, L. A., 1998. Assessment of Palaeoenvironmental Conditions on Southern Vancouver Island, British Columbia, Canada, Using the Marine Tychoplankter Paralia sulcata, Diatom Research. 13, 2, 311-321.

McQuoid, M. R., Nordberg, K., 2003. The diatom Paralia sulcata as an Environmental Indicator Species in Coastal Sediments, Estuarine, Coastal and Shelf Science. 56, 2, 339-354. https://doi.org/10.1016/S0272-7714(02) 00187-7

Melles, M. 1., Brigham-Grette, J., Minyuk, P. S., Nowaczyk, N. R., Wennrich, V., DeConto, R. M., Ander- 
son, P. M., Andreev, A. A., Coletti, A., Cook, T. L., HaltiaHovi, E., Kukkonen, M., Lozhkin, A. V., Rosen, P., Tarasov, P. E., Vogel, H., Wagner, B., 2012. 2.8 Million Years of Arctic Climate Change from Lake El'gygytgyn, NE Russia, Science. 337 (6092), 315-320. DOI: 10.1126/science. 1222135

Nedorubova, E. Yu., 2014. The Natural Environment of Chukotka 360-430 Thousand Years Ago (According to a Palynological Study of the Precipitation of Lake El'gygytgyn, Vestnik NESC FEB RAS. 4, 29-33 [In Russian].

Nedorubova, E. Yu., 2018. The Interglacial and Glacial Stages of the Middle Pleistocene in the Pollen Record of Lake El'gygytgyn (Central Chukotka), Bulletin of the North-East Scientific Center. 1, 32-38 [In Russian].

Olson, Storrs L., Hearty, Paul J., 2009. A Sustained + $21 \mathrm{~m}$ Sea-Level Highstand during MIS 11 (400 ka): Direct Fossil and Sedimentary Evidence from Bermuda, Quaternary Science Reviews. 28, 3-4, 271-285. https:// doi.org/10.1016/j.quascirev.2008.11.001

Pushkar, V. S., Cherepanova, M. V., 2001. Diatoms of Pliocene and Quaternary of the North Pacific. Vladivostok, Dal'nauka [In Russian].

Pushkar, V. S., Cherepanova, M. V., 2008. Diatom Assemblages and Correlation of Quaternary Deposits of the North-Western Pacific Ocean. Vladivostok, Dal'nauka [In Russian].

Pushkar, V. S., Cherepanova, M. V., 2011, Beringia: Impact on Paleoclimates of Northeast Asia and North Pacific during Last Pleistocene Glaciation, Quaternary International. 237, 1-2, 32-38. DOI: 10.1016/j.quaint. 2011.01.010

Pushkar, V. S., Cherepanova, M. V., Likhacheva, O. Y., 2013. Improvement of Diatom Zonal Scale of the North Pacific Pliocene and Quaternary, Pacific Geology. 32, 5, 52-66 [In Russian].

Pushkar, V. S., Cherepanova, M. V., Likhacheva, O. Y., 2014. Detalization of the Pliocene - Quaternary North Pacific Diatom Zonal Scale, International Journal on Algae. 16, 3, 284-306.

Pushkar, V. S., Cherepanova, M. V., Tarasova. E. V., 2019. Climatic Changes during MIS-5 of the Arctic Chukotka and Alaska, Bulletin of the North-East Scientific Center. 3, 27-36 [In Russian].
Pushkar, V. S., Razjigaeva, N. G., 2003. The PliocenePleistocene Golovnin Formation of Kunashir Island (the Kuriles): Stratigraphy and Formation Condition, Stratigraphy. Geological Correlation. 11, 5, 82-94 [In Russian].

Pushkar, V. S., Razjigaeva, N. G., 2003. The PliocenePleistocene Golovnin Formation of Kunashir Island (the Kuriles), Ibid. 11, 5, 492-504.

Pushkar, V. S., Razjigaeva, N. G., Korotky, A. M., Mokhova, L. M., 1998. The Late Golovnin Transgression of the Middle Pleistocene of the Kunashiri (Kuriles Islands), Ibid. 6, 6, 52-63 [In Russian].

Pushkar, V.S., Roof, S. R., Cherepanova, M.V., Hopkins, D. M., Brigham-Grette, J., 1999. Paleogeographic and Paleoclimatic Significance of Diatoms from Middle Pleistocene Marine and Glaciomarine Deposits on Baldwin Peninsula, Northwestern Alaska, Palaeogeography, Palaeoclimatology, Palaeoecology. 152, 67-85.

Raymo, Maureen E., \& Mitrovica , Jerry X., 2012. Collapse of Polar Ice Sheets during the Stage 11 Interglacial, Nature. 483, 453-456. DOI: 10.1038/nature 10891

Rohling, E. J., Braun, K., Grant, K., Kucera, M., Roberts, A. P., Siddall, M., Trommer, G., 2010. Comparison between Holocene and Marine Isotope Stage-11 Sea-Level Histories, Earth and Planetary Science Letters. 291, 97-105. DOI: 10.1016/j. eps1.2009.12.054

Wennrich, V., Minyuk, P. S., Borkhodoev, V. Ya., Francke, A., Ritter, B., Nowaczyk, N. R., Sauerbrey, M. A., Brigham-Grette, J., Melles, M., 2013. Pliocene to Pleistocene Climate and Environmental History of Lake El'gygytgyn, Far East Russian Arctic, Based on High-Resolution Inorganic Geochemistry Data, Climate of the Past. 9, 5899-5940. DOI: 10.5194/cpd9-5899-2013

Yin, Q. Z., Berger, A., 2010. Insolation and $\mathrm{CO}_{2}$ Contribution to the Interglacial Climate Before and after the Mid-Brunhes Event, Nature Geoscience. 3, 4, 243-246. DOI: https://doi.org/10.1038/NGEO771

Yin, Q., Berger, A., 2012. Individual Contribution of Insolation and $\mathrm{CO}$ to the Interglacial Climates of the Past 800,000 Years, Climate Dynamics. 38, 709-724. DOI: 10.1007/s00382-011-1013-5 